\title{
Por uma educação TRANSgressora e TRANSfeminista: possíveis enfrentamentos à produção das ausências através da disciplinarização e subjetivação
}

\author{
Fabio A. G. Oliveira \\ Liliana Rodrigues ${ }^{2}$
}

\begin{abstract}
Resumo: Este trabalho tem como objetivo problematizar, segundo uma perspectiva feminista crítica, o lugar das pessoas Trans no contexto educativo. Neste sentido, em um primeiro momento do trabalho, realiza-se uma revisão teórica sobre como os processos de categorização têm contribuído, em conjunto com as instituições e os discursos sociais, políticos e científicos, para a discriminação e violência contra as pessoas Trans. No segundo momento deste trabalho, se pretende problematizar o contexto educativo através de um encontro entre dois autores: Michel Foucault e Bell Hooks. Com o primeiro, se pretende apresentar conceitos-chaves (disciplina e subjetivação) para melhor entendermos a dinâmica que faz operar formas distintas de dominação no contexto neoliberal, cujo objetivo principal é a formação de consumidores-consumíveis, através do controle dos corpos e subjetividades. Ao final deste trabalho, propomos associar a discussão conceitual de Foucault à proposta da pensadora negra e feminista Bell Hooks sobre o importante papel da transgressão. Destacamos aqui as ausências sobre os corpos que escapam de uma normatividade endossada, promovida e elogiada por uma sociedade adicta a um padrão estéticopolítico associado a um tipo de consumo que reitera práticas heteronormativas interseccionadas a outras expressões da manutenção de poder e dominação que se consolidam através das transfobias.
\end{abstract}

Palavras-chave: Trans. Gênero. Feminismo. Educação.

\section{For a TRANSgressive and TRANSfeminist education: Possible confrontations against the production of absences through disciplinarization and subjectivation}

\begin{abstract}
This work aims to analyze, according to a critical feminist perspective, the place of Trans people in the educational context. In this sense, in the first moment of our work, a theoretical revision is made to understand how the processes of categorization have contributed, alongside with institutional, social, political and scientific discourses, to the discrimination and violence against Trans people. In the second moment of this work, we intend to problematize the educational context through a assembly between two authors: Michel Foucault and Bell Hooks. With the first one, we intend to present key concepts (discipline and subjectivation) to better understand the dynamics that make different forms of domination operate in the neoliberal context, whose main purpose is the formation of consumer-consumables, through the control of bodies and subjectivities. At the end of this paper, we propose to associate Foucault's conceptual discussion with the proposal of the black feminist Bell Hooks on the important role of transgression. We highlight here the absences of bodies that escape from a endorsed normativity, promoted and praised by a society addicted to an aesthetic-political pattern associated with a type of consumption that reiterates practices interspersed with heteronormative practices intersected with other expressions of the maintenance of power and domination that are consolidated through transphobia.
\end{abstract}

Keywords: Trans. Gender. Feminism. Education.

\footnotetext{
${ }^{1}$ Professor adjunto de Filosofia da Educação da Universidade Federal Fluminense (UFF). Membro permanente do Programa de Pós-graduação em Bioética, Ética Aplicada e Saúde Coletiva (PPGBIOS/UFF). Colaborador externo do Programa de Pósgraduação em Filosofia (PPGF/UFRJ). Coordenador do Laboratório de Ética Ambiental e Animal (LEA). E-mail: fabioagoliveira@gmail.com

${ }^{2}$ Professora adjunta do ISAVE - Instituto Superior de Saúde, Portugal. Pesquisadora Integrada do Centro de Psicologia da Universidade do Porto, Portugal.
} 


\section{Introdução}

Neste trabalho, será abordado a violência contra as pessoas que não conformam às normas de gênero. No sentido de uma melhor compreensão e localização da discussão em torno da designação "trans" (que inclui o conceito de "transexual", "travesti " e "transgênero"), adotar-se-á um conjunto de conceitos, reconhecendo-se, todavia, que os corpos e/ou identidades das pessoas não se reduzem a estes. Para designar as identidades que não conformam às normas de gênero, serão utilizados os seguintes conceitos: transexual, travesti e transgênero. Há quem os utilize como sinônimos e há quem os utilize como processos que abarcam trajetos diferentes (MISSÉ, 2014). No presente trabalho, será utilizada a designação "trans" porque as diferenças entre os termos supramencionados atenuam-se em determinados contextos e representam uma forma de resistência às normas de gênero impostas socialmente.

O conceito "transexual”" refere-se à pessoa que não se identifica com o sexo que lhe foi designado e atribuído ao nascer, pelo que esta mesma pessoa pode modificar o seu corpo através de procedimentos hormonais e/ou cirúrgicos. Contudo, apesar desta inconformidade de gênero/sexo, inúmeras pessoas transexuais não efetuam modificações corporais devido a motivos de natureza diversa (e.g. individual, sociocultural, econômica, etc.) (COLL-PLANAS, 2010). Além disso, a identidade de uma pessoa não deve ser reduzia a um corpo e aos dispositivos de "normalização" deste através da realização de uma ou várias cirurgias (RODRIGUES, 2016). O conceito de "travesti" refere-se às mulheres que foram designadas aquando do nascimento como homens e que constroem a sua identidade de gênero com diferentes expressões de feminilidade, incluindo, em muitos casos, modificações corporais (principalmente as hormonais), ainda que muitas travestis não realizem a cirurgia de redesignação sexual (ATT'TA, n. d.).

O desafio que se pretende neste trabalho é que se possa assumir um conjunto de categorias, ainda que sempre provisórias e sujeitas a um questionamento constante, bem como reconhecer que estas são falíveis e que não conseguem abranger toda a realidade das identidades (não conformes o sexo) (COLLPLANAS, 2012). De fato, como refere Jaqueline Gomes de Jesus (2012), quem define a identidade de uma pessoa é ela mesma e não uma cirurgia. No entanto, o fato dos Estados deterem os monopólios da violência física e da violência simbólica (BOURDIEU, 2002) forçam a que qualquer iniciativa que pressuponha o reconhecimento estatal tenha de ser legitimada por este, seja do ponto de vista jurídico, médico ou qualquer outro.

Diante deste quadro, aprofundaremos o conceito de transfobia e seus contextos e destacaremos a seguir de que maneira a transfobia pode ser pensada e problematizada, a partir de uma educação no contexto neoliberal. Para isso, analisaremos como as categorias de disciplinarização e subjetivação acabam por promover e acirrar as violências contra as pessoas trans. Neste sentido, buscaremos destacar a importância da epistemologia transfeminista para, de fato, a defesa de uma educação transformadora. 


\section{Transfobias: os "rankings das pessoas Trans no mundo"3}

A transfobia é um problema à escala mundial (PLATERO, 2014; TGEU, 2016). Entre 1 de janeiro de 2008 a 30 de abril de 2016, ocorreram 2115 homicídios contra pessoas trans no mundo. Neste ranking, o Brasil foi considerado o país com mais homicídios contra pessoas trans (TGEU, 2016). Também, de acordo com o Monitoramento da Rede Nacional de Pessoas Trans do Brasil (REDE TRANS BRASIL, 2016) e Relatório publicado pelo Grupo Gay da Bahia em 2017, foram totalizadas 347 mortes motivadas por LGBTfobia. Dentre essas mortes, $42,9 \%$ foram de pessoas trans, transexuais e travestis, o que significa um aumento de 6\% de crime de ódio contra pessoas trans no Brasil de 2016 para 2017 (GGB, 2017).

Enquanto problema à escala global, a transfobia não tem sido tratada com a devida atenção. Uma das maiores dificuldades no combate à transfobia consiste na resistência em reconhecer a relevância social das transexualidades (PLATERO, 2014), a qual se deve ao fato de inúmeros estudos sobre transexualidades estarem circunscritos ao modelo biomédico (e. g., BECERRA-FERNÁNDEZ, 2003; GARCÍA SISO, 2003; GÓMEZ GIL; ANTONIO, 2006; GÓMEZ GIL; TRILLA; SALAMERO; GODÁS; VALDÉS, 2009; IGLESIAS HERNANDEZ et al., 2010; LAWRENCE, 2010; MONEY, 1969). Estes estudos têm contribuído para a estigmatização social das pessoas trans. Além disso, ao localizarem o problema nas transexualidades, não questionam, nem problematizam as transfobias, pelo que têm originado referenciais negativos de intervenção que - em vez de acompanharem a pessoa na tomada da decisão sobre as suas identidades - têm servido como "guardiões" do sistema de sexo/gênero (COIMBRA, 1995; PLATERO, 2014).

Em Portugal, a 22 de fevereiro de 2006, na cidade do Porto, Gisberta Salce Junior, uma mulher trans brasileira, foi assassinada. Gisberta não era apenas uma mulher trans; Gisberta era também imigrante brasileira, soropositiva, toxicodependente, trabalhadora sexual e sem abrigo. A sua pertença a estes grupos sociais colocou Gisberta numa situação de extrema vulnerabilidade. Gisberta foi torturada por um grupo de jovens e posteriormente atirada para um poço. A sentença refere que esta tortura não "passou de uma brincadeira de mau gosto que terminou mal", negligenciando os reais motivos das agressões: a transfobia (OLIVEIRA, 2015; PANTERAS ROSA, 2006; RODRIGUES, 2016).

A transfobia tem sido definida como uma forma de discriminação, violência, ódio e rejeição contra pessoas trans ou contra aquelas que rompem com as normas de gênero socialmente impostas (JESUS, 2012; PLATERO, 2014). Além disso, também tem sido conceptualizada como uma forma de opressão para todas as pessoas pelas imposições de gênero, que tem como resultado: numa forma da sociedade oprimir as pessoas trans; na opressão de pessoas trans sobre outras e/ou na opressão sobre si

\footnotetext{
${ }^{3}$ Parte deste trabalho já foi publicado na seguinte referência RODRIGUES, L.; CARNEIRO, N. S., NOGUEIRA, C. (2017). Violência transfóbica: aproximações críticas e horizontes de resistência. In: NEVES, S.; COSTA, D. (Eds.). Violência de género. Lisboa: CIEG.
} 
mesma por ser trans - nesta última aceção remetendo para a habitualmente designada "transfobia internalizada" (CREIGHTON; KIVEL, 1992; LEWIS; ARNOLD, 1998; PLATERO, 2014; RODRIGUES, 2016). A transfobia internalizada pode também ser definida como o impacto da discriminação na forma de construir as subjetividades trans (MISSÉ, 2014).

As manifestações da transfobia podem ocorrer de várias formas, a saber: violência física, discurso de ódio, insultos (violência psicológica), exclusão e rejeição. O discurso estereotipado sobre gênero pode também ser uma forma de transfobia (BALZER; HUTTA, 2013). A transfobia tende a ser mais intensa na adolescência ou no início da vida adulta, tendo notórios impactos para o/a adolescente ou jovem adulto/a e para a sua família (CABEZAS; ORTEGA; GALÁN, 2013).

Inúmeros estudos identificaram os contextos de ocorrência de transfobia, nomeadamente os contextos escolar, laboral, familiar e do espaço público, entre outros. Em particular, tais estudos referem que os contextos escolares devem compreender e promover um panorama amplo e diverso de construção de significados de si e da construção da identidade (CABEZAS; ORTEGA; GALÁN, 2013; PLATERO, 2014; RODRIGUES, 2016). Além disso, mostram que, em contextos escolares menos receptivos para a inclusão da diversidade de expressões e/ou comportamentos de gênero, as crianças e os/as jovens que não conformam as normas de gênero podem sentir desconforto e [experimentar] uma construção negativa de si (e.g., CABEZAS; ORTEGA; GALÁN, 2013; PLATERO, 2014; BRITO, 2018). Quanto mais a ideologia deste contexto for rígida em relação às normas de gênero, mais as pessoas que não conformam as suas normas estão sujeitas à violência (GROSSMAN; D’AUGELLI; SALTER, 2006; SAUSA, 2005) e/ ou ao bullying transfóbico (e.g., PLATERO, 2014).

Ao nível do contexto laboral, as pessoas que não conformam o gênero que é imposto socialmente têm dificuldade em conseguir e manter um emprego. Este problema decorre não apenas do fato de ser trans, mas também de pertencer a outros eixos de opressão interseccionados, como classe social, orientação sexual, "raça"/etnia. Além disso, abandonar precocemente a escola, não ter apoio familiar aquando do coming out (sair do armário, se assumir) e, inclusive, ser expulso/a de casa; ter dificuldade de inserção profissional devido ao contexto de crise econômica e não conseguir obter facilmente a correspondência entre o gênero eleito e os documentos oficiais de identidade (GARCÍA NIETO, 2013; PLATERO, 2014) são fatores presentes na vida das pessoas trans que também têm influência nas oportunidades de realização ao nível laboral dos/as jovens trans. Muitos/as destes/as jovens têm vidas precárias, ostracizadas e estigmatizadas (Platero, 2014).

O estigma e a exclusão social associados a muitas experiências de vida trans fazem com que algumas pessoas recorram à prostituição, através da qual obtêm recursos financeiros para cobrir o tratamento hormonal e/ou cirúrgico (quando o desejam), bem como os custos diários de uma vida em situações recorrentes de ausência de qualquer respaldo social e familiar ${ }^{4}$. Em acrescento a esta situação

\footnotetext{
${ }^{4}$ De modo algum, esta afirmação induz ao posicionamento contrário ao exercício profissional da prostituição. Entretanto, vale destacar como a sociedade marginaliza e determina o destino geopolítico e social das pessoas trans, cerceando
} 
de vulnerabilidade, muitas pessoas trans estão sujeitas ao ódio transfóbico, o qual pode levar ao ostracismo social, à rejeição, à violência e a homicídios (SENNOTT, 2011). Em muitos locais no mundo, ter uma identidade trans coloca, assim, uma pessoa em risco de discriminação, violência e até morte (PLATERO, 2014; WHITTLE, 2006), como foi o mencionado caso da morte da Gisberta em Portugal (OLIVEIRA, 2015; PANTERAS ROSA, 2006) e muitos variados casos de homicídio motivados pela transfobia no Brasil (GGB, 2017).

Nestas situações, a responsabilidade das agressões tende a ser atribuída (quando o é) ao/à seu/sua perpetrador/a, não se problematizando as desigualdades sociais estruturais em que a violência se materializa, como se não houvesse um sistema ideológico subjacente (e.g. transfobia ou cissexismo, sexismo, homofobia ou heterossexismo, racismo, classismo, etc.), como se não houvesse um motivo neste caso específico, o ódio a determinados grupos - para as agressões.

Uma vez que as opressões estão interrelacionadas (NOGUEIRA, 2013), a transfobia não pode ser erradicada se não forem repensadas e transformadas as estruturas ideológicas que a reforçam, nomeadamente o sexismo e o binarismo de gênero (e.g., estipulação de entendimentos rígidos e polarizados sobre o que significam o "homem" e a "mulher") (CURRAH; JUANG; MINTER, 2006). No entanto, a destruição do sistema binário de gênero não é fácil: apesar de este limitar a vida das pessoas e sustentar a opressão, este sistema permite a identificação e a localização das pessoas no mundo. Além disso, as pessoas trans procuram, muitas vezes, nesse binarismo, uma legitimidade normativa e normativizante dos seus corpos e/ou das suas identidades (COLL-PLANAS; BUSTAMANTE I SENABRE; MISSÉ I SÁNCHEZ, 2010).

Por outro lado, um contexto apoiante, não patológico e que valoriza a diversidade ou as variações das expressões de gênero, poderá ter como resultado, uma maior aceitação de si, neste processo de atravessamento do gênero (GARAIZABAL, 2010; MIGUEL; VIERGE; ANTONIO, 2013; PLATERO, 2014; RODRIGUES, 2016). Tal como referem alguns estudos (e.g., COHEN-KETTENIS; OWEN; KAIJSER; BRADLEY; ZUCKER, 2003; PLATERO, 2014; ROBERTS; ROSARIO; CORLISS; KOENEN; AUSTIN, 2012; ZUCKER; BRADLEY, 1995), as crianças e jovens com gênero variante ou jovens trans estão mais vulneráveis à rejeição e opressão em sociedades onde o sistema cissexista e transfóbico atuam, principalmente nos contextos escolares e familiares, que policiam os comportamentos não normativos. Este policiamento não ocorre apenas pelos/as professores/as, pais e mães. Também, crianças e jovens em contexto escolar policiam os comportamentos de gênero dos seus pares (PEREIRA, 2012) e quando este comportamento rompe com as normas de gênero, a pessoa é discriminada e violentada (RODRIGUES, 2016).

Efetivamente, tal como refere Platero (2014), ao centrarmo-nos nas relações entre as pessoas trans e os seus contextos, leva-nos a ter que problematizar e a transformar as estruturas sociais que tentam

possibilidades múltiplas de exercício profissional. 
“disciplinar" as identidades das pessoas. Esse trabalho passa por reconhecer a responsabilidade destas estruturas no combate à discriminação e a não conceber as transexualidades ou variantes de gênero como problemas. O compromisso na erradicação da transfobia das estruturas sociais, como as escolas, os contextos laborais, e de saúde, juntamente com outros contextos de vida das pessoas, nomeadamente nos contextos familiares, implica assumir-se um conjunto de estratégias de combate à opressão e de proteção das pessoas (RODRIGUES, 2016).

Num estudo desenvolvido por Liliana Rodrigues (2016) foram identificados alguns “impactos das transfobias", a saber: menor expectativa média de vida; menores oportunidades de trabalho; problemas de saúde; invisibilidade das suas vidas; antecipação de dificuldades por ser trans; tentativas de suicídio; prostituição; negação social e "integração normativa" do corpo. São assim muitos e variados os impactos das transfobias nas pessoas trans, ou naquelas que rompem com as normas de gênero. Estes impactos são marcados, desde idade precoce, quando as crianças e jovens não conformes o gênero incorporam o discurso da sociedade, materializado nos contextos educacionais e familiares - reproduzem discursos de que o que fazem é mau, e, que por isso são más pessoas ou que têm uma doença mental. Esse tipo de discurso gera sofrimento nestes/as jovens (PLATERO, 2014; RODRIGUES, 2016).

Para além disso, vivem menos. A maior parte não chega a envelhecer. Estes dados corroboram as últimas pesquisas sobre crimes transfóbicos no mundo, tendo sido considerado o Brasil o país no mundo onde existe mais homicídios de pessoas trans (TGEU, 2016; GGB, 2017). Quando envelhecem deparamse com uma crescente vulnerabilidade nas suas vidas, que para além de pessoas trans, precárias, são também idosas (FERNÁNDEZ-ROUCO; SÁNCHEZ; GONZÁLEZ, 2012; LOPES, 2015; RODRIGUES, 2016; WITTEN, 2004).

\section{Uma epistemologia transfeminista para uma educação transformadora ${ }^{5}$}

Gênero e sexualidades são temas que têm ocupado a agenda de diversos campos dos saberes nos últimos anos. Na última década, presenciamos a criação de inúmeros laboratórios, núcleos e grupos de pesquisa sobre esses temas dentro das universidades ao redor do mundo. É possível afirmar que tal movimento se deu, sobretudo, por pressão dos movimentos sociais organizados que se consolidaram nas últimas décadas. Ao mesmo tempo, é preciso destacar que o enfoque dado ao discurso eurocentrado nos currículos, marcado pelo seu caráter colonial e liberal evidencia um abismo epistemológico, ético e político a ser superado para que tais debates, de fato, ecoem as demandas de grupos marginalizados, explorados e violentados historicamente. Diante desse quadro, corpos e vozes ausentes da produção do que se determinou como conhecimento tornam-se pouco a pouco “objetos” de estudos. Tal objetificação se insere dentro de um marco teórico que, segundo nossa perspectiva, se insere dentro do escopo do

\footnotetext{
${ }^{5}$ Parte deste trabalho foi apresentado durante a conferência de abertura do LEGESEX, da UFRRJ, em setembro de 2018.
} 
neoliberalismo.

\section{A educação no neoliberalismo e os modos de produção do corpo consumidor}

$\mathrm{O}$ advento do neoliberalismo trouxe para o indivíduo uma nova forma de estar e se compreender no mundo, desembocando em estilos de vida associados imediatamente ao consumo. Assim, o corpo passou a ser compreendido, nesse contexto, como espaço a ser ocupado, domesticado, docilizado e, consequentemente tornou-se mais um território geopolítico economicamente rentável. Ou seja, para que um indivíduo se torne um propagador de um estilo de vida coordenado pelo mercado, é preciso transformá-lo em um consumidor. Para isso, o ambiente escolar torna-se espaço fundamental a ser ocupado pelos interesses neoliberais, que objetivam a manutenção da ideia de sujeito enquanto consumidor e. em um só tempo, consumível. Por fim, é possível suspeitar da existência de um pacto de uma ideologia de mercado fortemente marcada pelas relações de poder disciplinares, entre aqueles que condicionam o indivíduo às raízes do individualismo e o empresariado, desembocando em um modelo de empresariamento da sociedade como um todo e da educação em particular. E como o corpo está situado nesta equação de empresariamento da sociedade?

De acordo com Foucault (1999), precisamos pensar nas modalidades disciplinares que servem como coerção ininterrupta. Ou seja,

Que vela sobre os processos da atividade mais que sobre seu resultado e se exerce de acordo com uma codificação que esquadrinha ao máximo o tempo, o espaço, os movimentos. Esses métodos que permitem o controle minucioso das operações do corpo, que realizam a sujeição constante de suas forças e lhes impõem uma relação de docilidade-utilidade, são o que podemos chamar as "disciplinas". Muitos processos disciplinares existiam há muito tempo: nos conventos, nos exércitos, nas oficinas também. Mas as disciplinas se tornaram no decorrer dos séculos XVII e XVIII fórmulas gerais de dominação (FOUCAULT, 1999, p. 164).

A citação anterior nos permite inferir que o ato disciplinar não seja invenção moderna, pois, tal qual afirma Foucault, muito antes da modernidade de formas de dominação através da disciplina já se encontravam presentes em espaços, tais quais: quartéis e conventos. A partir do século XVIII a ideia de disciplina sofre várias transformações, a fim de aumentar a utilidade dos indivíduos; ou seja, deixa de estar circunscrita pelos limites institucionais e passa a compor e estruturar as relações de dominação em outros espaços sociais.

A disciplina pode ser entendida, então, como uma forma de exercício de poder, um dispositivo, ou seja, "uma rede de relações entre elementos heterogêneos [instituições, construções, regulamentos, discursos, leis, enunciados científicos, disposições administrativas]" (CASTRO, 2015, p.93) que ocorre com uma determinada finalidade estratégica. Ou seja, uma rede que visa forjar os indivíduos, a partir da lógica de uma cadeia produtiva. Indivíduos politicamente dóceis e economicamente rentáveis, com o propósito central de modificá-los e adaptá-los às novas disposições sociais e econômicas. Dessa forma, 
as diferentes formas de disciplina subsistem sobre uma fundamentação de técnicas. Pensemos, por exemplo, salas de aula, hospitais, presídios ou mesmo os escritórios de agentes económicos. Através desses exemplos podemos imaginar uma arquitetura da disciplina.

A distribuição de corpos em um espaço quadriculado e articulado, definindo em relação a uma determinada função e ordenando em termos classificatórios: cada preso em sua cela, cada doente em sua cama, cada aluno na sua carteira, cada empregado em seu escritório ou junto a sua máquina. Em segundo lugar, o controle da atividade mediante o horário e o ajuste dos comportamentos e gestos à temporalidade de um processo. Em terceiro lugar, a organização genética do tempo, mediante a segmentação da temporalidade de um processo e a serialização de atividades repetitivas e sucessivas. E, finalmente, a composição das séries temporais mediante uma estrita linha de mando (CASTRO, 2015, p. 93).

Para Foucault, essas instituições não excluem simplesmente os corpos, mas os sequestram, sujeitando o tempo e a vida dos sujeitos ao tempo de produção. Ou seja, pretende preencher e ocupar todo o espaço de tempo desses indivíduos com a suposta necessidade de atividades produtivas. "Assim, a disciplina fabrica corpos submissos e exercitados, corpos dóceis" (FOUCAULT, 1999, p. 164). Tais corpos são treinados a compreender a vida como um exercício constante que visa primordialmente a movimentação do mercado.

O momento histórico das disciplinas é o momento em que nasce uma arte do corpo humano, que visa não unicamente o aumento de suas habilidades, nem tampouco aprofundar sua sujeição, mas a formação de uma relação que no mesmo mecanismo o torna tanto mais obediente quanto é mais útil, e inversamente. Forma-se então uma política das coerções que são um trabalho sobre o corpo, uma manipulação calculada de seus elementos, de seus gestos, de seus comportamentos (FOUCAULT, 1999, p. 164).

Justamente o que enfatiza o nascimento da disciplina é a compreensão do corpo [humano] enquanto conjuntura, sendo parte do ser em si não somente compreendido como algo biológico estudado pela biologia -, mas um ser que está ligado às demais relações ao seu redor; corpo pensante e presente no espaço que dialoga e que intervém no meio social. E através da compreensão do corpo constituído como construção histórica e social, marcado pelo meio ao qual pertence, que o corpo cumpre a tarefa de instrumento para a constituição de uma subjetividade, igualmente dominada e sequestrada. $\mathrm{O}$ indivíduo, composto pelo corpo e subjetividade, se tornaria uma forma, um sujeito. Tal forma torna-se um campo de disputa em meio às relações de poder que constituem as sociedades nas quais esse sujeito está inserido e sendo formado. Neste sentido, as instituições que produzem esse "tipo de corpo" acaba também por ausentar outros corpos que escapam à norma estruturada por essas relações. Ou seja, a instituição que produz um modelo de indivíduo o produz através da normatização do corpo e da subjetividade.

De acordo com Foucault, o sujeito não é uma substância, mas se aproxima a uma forma. Tal forma, em cada relação, se posiciona e se elabora de diferentes maneiras. Consequentemente, há possibilidade de haver diferentes processos de subjetivação. Foucault pretende demonstrar com isso a 
existência de diversas maneiras pelas quais os indivíduos se tornam sujeitos. Os processos de subjetivação, desta maneira, serão os modos pelos quais os indivíduos se constituem enquanto sujeitos.

Posto isso, pode-se dizer que, em Foucault, a constituição do sujeito - o processo de subjetivação - envolve algumas etapas, dentre elas as práticas de si, que por sua vez se relacionam com aspectos éticos do poder e do saber. Através de um conduzir-se, mediante o escopo de constituir-se a si mesmo, perpassado por uma referência de códigos que estruturam esses sujeitos, se institui uma norma. Sujeitos que através desse processo de constituição de si, obedeçam às prescrições e submetam-se às normas - a modos de sujeição - supondo assim que não seja possível a constituição deste sujeito moral, sem que ocorra o processo de subjetivação do mesmo.

Este sujeito é, portanto, resultado de práticas de poder que disputam um corpo e uma subjetividade, no sentido de tentar nos dominar e docilizar. Através da análise histórica dos poderes, Foucault mostra que se vive, naquilo que se chama de modernidade, três modelos de exercício de poder: o de soberania, o disciplinar e o biopoder. Os quais não se excluem, mas sim se complementam. O campo das tecnologias disciplinares é construída no mesmo âmbito que a soberania; ou seja, como uma forma de domar os corpos dos indivíduos. O que Gallo e Veiga-Neto (2007, p. 9) descrevem como: “[...] a própria noção moderna de indivíduo [sendo] um efeito de exercícios de poder [...]”. Assim, a tecnologia do biopoder emerge sobre um novo exercício, sobre o corpo político coletivo: a população; pois seria justamente o biopoder que permitiria a governabilidade da população. Deste modo, a tecnologia da disciplina tem por objetivo a sujeição do corpo do outro para torná-lo mais dócil, manipulável. Ou seja, a tecnologia do biopoder é exercida e tem impacto direto sobre o corpo político coletivo. Diante deste discurso, "a biopolítica faz nascer à seguridade social” (GALLO; VEIGA-NETO, 2007, p. 10). Em resumo, pode-se dizer que a própria noção de Estado de bem-estar nasceu sob o teto do biopoder, com o propósito de controle da população.

Neste sentido, propomos uma reflexão sobre uma questão acerca do biopoder e sua relação íntima com as práticas pedagógicas, em especial no modo como tais práticas podem estar intimamente comprometidas com a mercantilização e docilização dos pensamentos e corpos trans por um lado, e por outro com a reiteração de práticas de discriminação diretas e indiretas sobre este grupo de pessoas. Por qual razão mesmo no século XXI ainda podemos identificar dispositivos disciplinares tão presentes nas salas de aula? Seria o neoliberalismo uma ferramenta de suporte essencial à manutenção de métodos disciplinares? Teria o neoliberalismo instituído um modelo que produz o individualismo e o auto empresariamento no modelo de manutenção do espaço escolar? Por que o ambiente de sala de aula pode ser tão perverso com sujeitos que escapam da norma esperada? Seriam os corpos cisheterodiscordantes não somente uma fissura na norma, mas uma denúncia ao processo de ausência que as próprias instituições de ensino produzem?

Trata-se de pensar, portanto, como a educação pode participar ativamente da produção e descarte dos indivíduos desde a sociedade moderna. Tendo sido destinado às escolas, o espaço formal onde se 
produz e se acessa o conhecimento científico, qual seria o seu papel diante de uma sociedade marcada pelo objetivo de não emancipar indivíduos a sujeitos livres e autônomos, mas a sujeitos consumidores e consumíveis que reiteram preconceitos e atos discriminatórios injustificáveis? E quais subjetividades as salas de aula ajudariam a produzir e a ausentar neste processo de mercantilização do pensamento? Essas questões refletem um universo de preocupação que nos permite melhor compreender o papel da educação na discussão sobre as teorias de gênero e sexualidades, dando destaque aqui ao papel da educação transgressora como prática de liberdade, tal qual sugere bell hooks.

Aqui é preciso destacar que a consolidaçào do sistema sexo-gênero fez e faz operar inúmeras violências estruturantes contra mulheres e pessoas LGBTQIA+ de modo geral e específicos. A docialização de corpos, a qual se refere Foucault, e o enquadramento dos desejos, como propõe Butler, continua sendo alvo de inúmeros projetos da prática de cerceamento de liberdades. A cisheteronormatividade, aliada ao projeto sexista contra as mulheres e ao racismo contra a população negra, se estruturou nas bases da lógica que forja a colonização do outro, produzindo diferentes formas e níveis de ausências e ocultamentos. O classismo, racismo, eurocentrismo, especismo entre tantos outros modos de violência contra todos e todas consideradas "outro" acabaram por consolidar, como acompanhamos com Foucault, a normatização dos corpos e desejos. Neste percurso, se configurou um projeto epistemológico, estético e ético-político bastante específico de produção de conhecimento autorizado, sob a pretensão da neutralidade de um lado, e de outro fez e faz operar a materialização dos discursos e atos de violência contra grupos marginalizados neste processo. De acordo com Boaventura (2010), as epistemologias neutras não existem, e são menos neutras aquelas que tencionam demonstrar essa neutralidade. Subsidiariamente, são nas práticas de conhecimento e nos seus reflexos em outras práticas sociais que a reflexão epistemológica também deve debruçar-se. É com base nessas ideias e noções que devemos analisar e discutir o reflexo do colonialismo e do capitalismo modernos nas ciências e nos processos de formação das epistemologias dominantes e, em nosso caso, na produção de ausências que refletem nos corpos cisheterodiscordantes. Isto se dá ao fato de que o conjunto de dominações geralmente conhecidas, a dominação colonial, é igualmente uma dominação epistemológica. Desta dominação surgem as ausências. E deste diagnóstico nos perguntamos: haveria alguma forma de transgredir esse processo de produção do corpo cisheterodiscordante ausente?

\section{bell hooks e os caminhos para uma educação transgressora}

Um possível ensaio à pergunta feita é oferecida pela proposta metodológica de bell hooks, em que a pensadora feminista, na obra Ensinando a transgredir (HOOKS, 2013), afirma que a educação pode se tornar um lugar possível, de encontros e cuidados. A pedagogia crítica e a educação de liberdade seriam, para hooks, as bases de uma proposta que visa demonstrar a importância da educação como prática social. 
Para hooks (2013), ensinar estudantes a transgredirem as fronteiras raciais, sexistas e de classe, a fim de alcançarem o dom da liberdade, deve ser o objetivo mais importante daquele ou daquela que ocupe o lugar de educador e educadora. Ou seja, pensar a educação pressupõe o reconhecimento do lugar do sujeito pensante: o sujeito localizado. Nesse sentido, a autora propõe uma reflexão sobre a epistemologia da educação. hooks comenta:

Neste livro, quero partilhar ideias, estratégias e reflexões críticas sobre a prática pedagógica. Quero que estes ensaios sejam uma intervenção - contrapondo-se à desvalorização da atividade do professor e, ao mesmo tempo, tratando da urgente necessidade de mudar as práticas de ensino (HOOKS, 2013, p. 21).

Para alcançar este objetivo, hooks investigou a sala de aula não somente como um espaço de encontro e trocas, mas também como fonte de constrangimento. Deste emaranhado de possibilidades, hooks pretende defender o espaço da sala de aula como uma fonte potencial de libertação que precisa encarar seus desafios inerentes ao processo da partilha de falas e discursos. A autora chama atenção para o fato de alguns professores e professoras usarem do controle e do poder sobre os alunos e as alunas para a condução das aulas. Segundo ela, essa atitude faz produzir um sentimento de opressão, quando na verdade o espaço de sala de aula deveria promover o entusiasmo. Para ela, esse entusiasmo já poderia ser considerado como um ato de transgressão, pois para exercê-lo em sala de aula o professor e a professora deveriam reconhecer que as práticas pedagógicas antes exercidas não poderiam continuar sendo as mesmas. Logo, seria preciso romper com o ensino tradicional e permitir mudanças e reflexões críticas no ensino/aprendizado.

Para hooks (2013), Paulo Freire é um grande aliado para nos ajudar a pensar a realidade social visando a uma forma libertadora para experimentar o ensino/aprendizagem. Através de Freire, hooks afirma ter conseguido desenvolver uma linguagem e pensar na construção de uma identidade de resistência, na época em que lutava pela dessegregação racial. Nesse sentido, se apropriar de uma linguagem que desse sentido àquilo que ela própria vivia, foi uma forma de se libertar. Libertar implica, neste contexto, poder nomear um fenômeno social de sofrimento que até então não tinha nome. Não possuir uma linguagem política para formular aquele processo de resistência era difícil para poder pensar e reformular os processos de injustiças inerentes a ele. hooks comenta:

Uma frase isolada de Freire, se tornou um mantra para mim: 'Não podemos entrar na luta como objetos para nos tornarmos sujeitos mais tarde’. Realmente é difícil encontrar palavras adequadas para explicar como esta afirmação era uma porta fechada - e lutei comigo mesma para encontrar a chave - e essa luta me engajou num processo transformador de pensamento crítico (HOOKS, 2013, p. 67).

hooks considera Freire um professor que alimenta suas forças na luta contra o processo de colonização que gera e faz introjetar a mentalidade colonizadora. Diante da mentalidade colonizadora que faz com que grupos de indivíduos subalternizados pensem através da mente daquele que os coloniza, hooks aponta para um caminho de libertação deste processo quando identifica um elo entre o processo decolonial e o pensamento de Freire sobre a "conscientização". Para ela, o início da transformação 
começa quando começamos a pensar criticamente sobre nós mesmos, e como a nossa identidade diante das circunstâncias políticas foi projetada. De acordo com hooks, esse é o pensamento de Freire em seu entendimento global das lutas de libertação. Por isso, hooks chama a atenção para o que admira na obra de Freire: a práxis. O pensamento reflexivo seria ele mesmo uma forma de desvendar concretamente as amarras que fazem com que pensemos sobre o mundo de um determinado modo e sobre nós mesmos na interação com ele. Neste encontro entre mundo e eu no mundo, somos forjados a pensar sobre nós mesmos em uma articulação sobreposta. Diante deste processo de desvendar quem somos, em um mundo marcado pela colonização dos territórios e de alguns grupos vulnerabilizados historicamente, hooks chama atenção para "a necessidade de tornar real na prática o que já sabemos na consciência" (HOOKS, 2013, p. 68). Ou seja, a autora acredita que muitos movimentos políticos progressistas não conseguem resultados de transformação duradoura porque não possuem uma compreensão real sobre a “práxis", não compreendendo que a mudança começa em ações cotidianas, em suas práticas que forjam uma concepção específica de indivíduos. É preciso, portanto, ter alguma ideia sobre quem se é para, então, aderir a um movimento que efetivamente expresse quem somos e nossas concepções mais básicas da vida que queremos viver, que aspiramos construir. Sem essa etapa de entender quem se é diante de um mundo colonizado não haveria liberdade para saber quem se é e quais lutas travar.

Em pedagogia engajada, primeiro capítulo da obra Ensinando a Transgredir (HOOKS, 2013), hooks afirma como a obra de Paulo Freire a ajudou a compreender as limitações das práticas pedagógicas que ela havia tido quando ainda era aluna, e comenta que a obra de Freire a inspirou no ato de revisitar os afetos que ela nutria por professores que a incentivaram a transgredir em seus estudos, quebrando todos os paradigmas que tratavam a educação como uma linha de produção. Inspirada em Freire e no monge budista vietnamita Thich Nhat Hanh, hooks entende que os professores e estudantes devem ser vistos em sua integralidade, a união de mente, corpo e espírito. Portanto, ela acredita que as experiências vividas por professores e professoras e estudantes fora da escola poderiam, sim, ter uma ligação com seu ensino/aprendizado dentro do ambiente escolar. Ignorar os fatores da vida seria uma forma de compreensão fragmentada e segmentada da prática pedagógica e afastá-la da vida. Se referindo ainda ao trabalho de Freire, hooks afirma que

[...] sua abordagem holística ao aprendizado e à prática espiritual me permitiu vencer anos e anos de socialização que haviam me levado a acreditar que a sala de aula perde importância quando os alunos e professores encaram uns aos outros como seres humanos "integrais", buscando não somente os conhecimentos que estão nos livros, mas também o conhecimento acerca de como viver o mundo (HOOKS, 2013, p. 27).

Depreende-se desta afirmação que hooks reconhece a importância das experiências dos indivíduos fora de sala de aula para uma compreensão da pedagogia e, mais especialmente na reflexão de uma pedagogia transgressora. Para hooks, há uma ligação entre as experiências pessoais, ou seja, a prática de vida desses sujeitos e seu comportamento na sala de aula. Ela acredita que não há como separar ambos, 
pois além de ambos estarem interligados, toda vez que se investe em uma separação reforçamos a produção de um silêncio, de uma impossibilidade de dizer, reconhecer e, por fim, existir em sala de aula. Nesse sentido, hooks aponta para a necessidade de criação de novas estratégias de ensino/aprendizagem que levem em consideração os aspectos da vida em sua forma mais plena.

hooks afirma que as práticas pedagógicas tradicionais não conseguem mais envolver os estudantes e as estudantes no processo de aprendizagem, pois muitas vezes ainda fazem essa separação entre mente e corpo. Um exemplo a ser dado é quando um aluno ou uma aluna no meio da aula se manifesta, contando uma experiência, ou um assunto que a princípio "não tem a ver" com o conteúdo que o professor ou a professora está expondo, e pelo fato do professor ou da professora não estar preparado ou preparada para lidar com esta situação, acaba constrangendo o ou a estudante, reforçando a sua dominação em sala de aula. Para hooks, é preciso tentar compreender o motivo pelo qual muitas vezes não se consegue estabelecer esse diálogo entre professor ou professora - estudante. Ou seja, não se cria uma estratégia que possa conectar efetivamente o que o ou a estudante está falando com o conteúdo que está sendo apresentado. Embora em um primeiro momento pareça ao professor ou à professora que não há ligação (explícita) entre o conteúdo ensinado e a fala do ou da estudante, talvez na mente do indivíduo haja. Como tentar compreender esse processo de reflexão do sujeito que acionou experiências aparentemente outras e desconexas para se conectar com aquele conteúdo ministrado? Como podemos criar pontes?, pergunta hooks.

Diante de um cenário de sala de aula sem conexão entre professor ou professora e estudantes, hooks afirma que estudantes já não querem mais ser considerados como indivíduos que estão em sala somente para memorizar o que os professores ou as professoras transmitem. Há uma necessidade dos e das estudantes de serem vistos e vistas como seres integrais; além dos conhecimentos escolares, eles e elas desejam ter conhecimento sobre a vida. Segundo hooks, suas experiências complexas de vida já não podem mais ser separadas das experiências vividas na escola. Tanto os professores e as professoras quanto os e as estudantes, mesmo que inconscientemente, desejariam algo que os libertassem. Para hooks, este desejo é a vontade por uma educação que não seja apenas transmissão de conhecimentos, como uma educação bancária, mas uma educação da e para a vida. hooks chega a afirmar estar atormentada com a realidade das salas de aula que, segundo ela, se caracterizam muitas vezes como espaços usados para a opressão, ou seja, um exercício injusto de poder. Portanto, a autora propõe que observemos cuidadosamente a relação entre professores/as e estudantes, sob a ótica de uma intervenção pedagógica necessária: contrapondo-se à desvalorização das atividades dos/as professores/as, criando estratégias para as salas de aula que considerem professores/as e estudantes enquanto participantes ativos no ensino/aprendizagem. A união dessas frentes caracterizaria o que hooks chama de "pedagogia engajada". Essa pedagogia, segundo hooks, tem um compromisso basilar com a prática da liberdade.

Como professora, hooks passou a perceber melhor o tamanho do desafio de trabalhar com educação numa perspectiva libertadora. A partir da pedagogia engajada, hooks pretende questionar os 
sistemas de dominação ocultos nas escolas, manifestados nos mais diferentes discursos e silêncios naturalizados que registram o racismo, as desigualdades de classes, sexismo, entre outros aspectos sobre os quais a sala de aula muitas vezes não anuncia. Para hooks, trazer à superfície tais marcas, segundo ela cruciais no modo de construção dos indivíduos, dentro e sala de aula, exige da pedagogia o engajamento necessário por parte do/a professor/a, na valoração da experiência dos e das estudantes. A valoração dessa experiência é o caminho, segundo hooks, que garante o bem-estar de todas as partes envolvidas no processo de ensino/aprendizagem.

hooks diz:

A educação progressiva e holística, a "pedagogia engajada", é mais exigente que a pedagogia crítica ou feminista convencional. Ao contrário destas duas, ela dá ênfase ao bem-estar. Isso significa que os professores devem ter o compromisso ativo com um processo de auto-atualização que promova seu próprio bem-estar (HOOKS, 2013, p. 28.

hooks acredita na autoatualização. Ou seja, para a autora o professor ou a professora deve estar engajado/a na realidade que visa a buscar a libertação de todos que fazem parte do processo de ensino/aprendizagem. Desta forma, o processo de autoatualização promoveria o bem estar do indivíduo e o prepara para os desafios impostos pelo ensino. Para hooks, é preciso estar bem consigo mesmo, para depois pensar em como ensinar alguém. Sendo assim, a pedagogia engajada é aquela que permite avaliar o bem-estar de professores/as e estudantes. Com isso, evidencia os constrangimentos psicossociais que afetam diferentemente as partes do processo. Para a autora, é fundamental reconhecer o papel que as emoções possuem em nossos atos. E é por essa razão que se engajar na vida de forma ampla nos oferece condições de melhor compreender as dimensões e caminhos possíveis para compartilharmos experiências e conhecimento. hooks credita ao seu encontro com os escritos de Paulo Freire o despertar para a necessidade de romper com os paradigmas do ensino dominante daquela época, e descobrir outras alternativas de aprender e ensinar. A autora diz:

Minha experiência com ele me devolveu a fé na educação libertadora. Eu nunca quisera abandonar a convicção de que é possível dar aula sem reforçar os sistemas de dominação existentes. Precisava ter certeza de que os professores não têm de ser tiranos na sala de aula (HOOKS, 2013, p. 31).

hooks defende, portanto, que a sala de aula deveria ser um espaço empático, com respeito às multiplicidades. Neste sentido, a sala de aula seria uma espécie de espaço rizomático, onde a educação não estaria voltada somente para a figura do/a professor/a como detentor(a) de conhecimento, ou no/a estudante enquanto receptáculo, mas em uma forma de troca de experiências de vida que conectadas ao conteúdo programático promoveriam um dispositivo de pensar-junto (TIBURI, 2008).

hooks defende a adoção de uma metodologia não-linear de ensino, propondo fugir dos padrões regulares metodológicos. Ela defende que através da troca, do compartilhar, seria possível desenvolver pensamentos críticos no aprendizado.

A pedagogia engajada demonstra isso quando defende a valorização da expressão do/a estudante, 
por exemplo. Essa seria a própria prática da liberdade. hooks diz:

Quando a educação é a prática da liberdade, os alunos não são os únicos chamados a partilhar, a confessar. A pedagogia engajada não busca simplesmente fortalecer e capacitar os alunos. Toda sala de aula em que for aplicado um modelo holístico de aprendizado, será também um local de crescimento para o professor que será fortalecido e capacitado por este processo. Este fortalecimento não ocorrerá se nos recusarmos a nos abrir ao mesmo tempo em que encorajamos os alunos a correr riscos (HOOKS, 2013, p. 35).

A pensadora acredita que quando o/a professor/a espera que os/as estudantes partilhem narrativas, mas eles/as mesmos/as não o fazem, estão exercendo o poder na sala de aula, e reforçando uma espécie de dominação. Segundo hooks, é preciso que o professor ou a professora dê o primeiro passo: ele/a deve ser o/a iniciador/a do processo de fissura da pedagogia tradicional. Ou seja, aquele ou aquela que expõe as narrativas da sua própria experiência nas discussões teóricas em sala de aula, dando sentido à teoria, permitindo assim que os/as alunos/as se sintam à vontade para igualmente expor as suas concepções a ponto de se envolverem com a teoria e, quem sabe, se encontrarem nela. Haveria, portanto, uma espécie de confissão no processo de se engajar na teoria. Fazendo deste modo, o/a professor/a elimina a possibilidade de tornar sua prática tradicionalista, e permite que ela se torne libertadora para ele/a mesmo/a e para os/as estudantes.

hooks afirma que

[...] É produtivo, muitas vezes, que os professores sejam os primeiros a correr o risco, ligando as narrativas confessionais às discussões acadêmicas para mostrar de que modo a experiência pode iluminar e ampliar nossa compreensão do material acadêmico (HOOKS, 2013, p. 36).

Para a autora, os professores e as professoras que colocam em prática a autoatualização, são os/as mais preparados/as para criar práticas pedagógicas que não reforcem o sistema de dominação, e nem a parcialidade, mas que lutam para criar estratégias que proporcionem aos/às estudantes a oportunidade de se tornarem críticos/as, aumentando sua capacidade de viver profundamente. Nesse sentido, hooks defende que a sala de aula precisa ser compreendida como um lugar não de autoritarismo e transmissão de conteúdos, mas de aprendizado mútuo. Para ela, precisamos ir em busca de um ensino que permita a transgressão, criação de um movimento que transforme a educação na prática da liberdade concreta, e que vincule teoria à prática de todos/as os/as envolvidos/as. Só assim, segundo hooks, conseguiremos mudar o atual cenário educacional que vivemos nos dias de hoje.

Para hooks, a mudança deste cenário prevê uma educação capaz de promover mudanças de mentalidade. Toda liberdade de pensamento, fruto de uma reflexão crítica e não autoritária, sugere estremecimentos na estrutura política vigente. Por isso, hooks reconhece que há inúmeras barreiras fincadas no sistema de dominação contrárias à pedagogia engajada. Afinal, na pedagogia engajada percebemos a importância que a autora dá à educação como prática social humanista, que precisa do empenho, e de muito trabalho por parte de todas as pessoas que integram o processo educativo. Esta mudança é passo crucial para a liberdade. 
hooks chega a sugerir, portanto, que a universidade pode se tornar um lugar para navegarmos.

$[\ldots .$.$] a academia não é o paraíso, mas o aprendizado é um lugar onde o paraíso$ pode ser criado. A sala de aula com todas as suas limitações continua sendo ambiente de possibilidades. Nesse campo de possibilidades, temos a oportunidade de trabalhar pela liberdade, exigir de nós e de nossos camaradas uma abertura da mente e do coração que nos permite encarar a realidade ao mesmo tempo em que, coletivamente, imaginemos esquemas para cruzar fronteiras, para transgredir. Isso é a educação como prática da liberdade (HOOKS, 2013, p. 273).

A universidade passa a ser, portanto, um lugar possível; um espaço de potencial produção de resistência e liberdades, o que acaba por implicar na problematização de seus métodos e conteúdos.

\section{Considerações finais}

Tal como foi referido ao longo do trabalho, as crianças e jovens trans estão mais expostos/as e suscetíveis à violência em contexto escolar, seja de forma discursiva, pelas ausências ou através de práticas mais explicitas de opressão. Especificamente, os contextos escolares tendem a policiar as expressões e identidades de gênero das crianças e jovens através dos/as professores/as, de outros agentes educativos, pais e mães e de outras crianças e jovens (PEREIRA, 2012). Quando as crianças rompem com o comportamento ou expressão de gênero normativos tendem a ser discriminadas e violentadas (Rodrigues, 2016). Neste contexto, o sistema educativo serve como guardião do sistema de sexo/gênero, disciplinando os corpos e identidades discordantes (COIMBRA, 1995; PLATERO, 2014) e/ou construções de gênero plurais.

Deste conjunto de reflexões nasce uma pedagogia crítica capaz de fazer emergir o pensamento através do exercício da própria liberdade. Deste lugar de possibilidades, das salas de aula, propomos um pensamento-agência. Ou seja, um dispositivo conceitual que teoriza ao mesmo tempo que não objetifica, dado que disputa a produção de conhecimento coletiva e horizontalmente e não vertical e isoladamente.

Neste sentido, um pensamento-agência abre os caminhos para novas epistemologias dissidentes, fissurando um silêncio acadêmico a respeito da produção de narrativas acerca das vivências não previstas pelas normatizações incorporadas pelas próprias instituições de ensino formais.

Dito isso, buscamos destacar a importância epistemológica de se pensar gênero e sexualidade e educação diante dos conceitos de disciplina e subjetivação propostos por Foucault. Para além disso, sublinhamos a importância de contextualizarmos este debate dentro do panorama neoliberal que estimula a todas e todos nós assumirmos o nosso papel de consumidores-consumíveis, na contramão de uma educação transgressora e de uma pedagogia engajada como prática de liberdade, como propõe bell hooks. Pensar desta maneira, defendemos, fortalece a possibilidade de refletirmos a importância de uma produção de saber-agenciado, que rompa com o silenciamento e ausência de alguns em detrimento de outros, na mesma medida que nos fortalece enquanto grupo, na sua multiplicidade de vozes, corpos, cores e discursos. Aqui somos em um só tempo o questionamento e a transgressão. 


\section{Referências}

ATTTA (n.d.). Derecho a la i9dentidad: ley de identidad de género y ley de atención integral de la salud para personas trans. Disponível em: www.attta.org

BALZER, C.; HUTTTA, J. S. Transrespeto versus Transfobia en el Mundo: un studio Comparativo de la situación de los derechos humanos de las personas Trans. Serie de publicaciones de tvt, 7 , Transgender Europe, 2013. Disponível em: http://www.transrespecttransphobia.org/uploads/downloads/Publications/TvT_research-report_ES_.pdf

BECERRA-FERNÁNDEZ, A. Tratamiento hormonal de los trastornos de identidad de género: efectos beneficiosos y efectos adversos. In: BECERRA-FERNÁNDEZ, A. (Ed.). Transexualidad: la búsqueda de una identidade. Madrid: Ediciones Díaz de Santos S. A, 2003.

BOURDIEU, P. A dominação masculina. 2 ed. Rio de Janeiro: Bertrand Brasil. 2002. Disponível em: https://www.sertao.ufg.br/up/16/o/BOURDIEU_Pierre._A_domina\%C3\%A7\%C3\%A3o_masculin a.pdf?1332946646

BRITO, S. Infância(s) e género(s): a normativização da expressão de género na infância. Dissertação de Mestrado Integrado em Psicologia. Faculdade de Psicologia e de Ciências da Educação da Universidade do Porto, 2018.

CABEZAS, L. P.; ORTEGA, E.; GALÁN, J. I. P. Adolescentes transexuales en las aulas. Aproximación cualitativa y propuestas de intervención desde la perspectiva antropológica. In: CABRERA, O.; CABEZAS, L. (Eds.). Transexualidad, adolescencias y educación: miradas multidisciplinares. Barcelona, Madrid: Egales Editorial, 2013.

CASTRO, E. Introdução a Foucault. Trad. Beatriz da Almeida Magalhães. Belo Horizonte: Autêntica, 2015.

COHEN-KETTENIS, P.; OWEN, A.; KAIJSER, V.; BRADLEY, S.; ZUCKER, K. Demographic characteristics, social competence, and behavior problems in children with gender identity disorder: a cross-national, cross-clinic comparative analysis. Journal of Abnormal Child Psychology, n. 31, v. 1, 41-53, 2003.

COIMBRA, C. Guardiães da ordem: uma viagem pelas práticas psi do Brasil do milagre. Rio de Janeiro: Oficina do Autor, 1995.

COLL-PLANAS, G. Indroducción. In: MISSÉ, M.; COLL-PLANAS, G. (Eds.). El género

desordenado: Críticas en torno a la patologización de la transexualidad. Barcelona: Egales, 2010.

" "El circo de los horrores". Una mirada interseccional a las realidades de lesbianas, gays, intersex y trans. In: PLATERO, R. L. (Ed.). Intersecciones: cuerpos y sexualidades en la encrucijada. Temas contemporâneos. Barcelona: Edicions Bellaterra, 2012.

BUSTAMANTE I SENABRE, G., MISSÉ I SÁNCHEZ, M. Strategies, trajectories and contributions of young transsexuals, lesbians and gays. Catalunya: Departament d'Acció Social i Ciutadania e Secretaria de Joventut, 2010. Obtido em:

http://benestar.gencat.cat/web/.content/documents/arxiu/publicacions/col_aportacions/aportacions _40.pdf 
CREIGHTON, A.; KIVEL, P. Helping teens stop violence: a practical guide for counselors, educators, and parents. Alameda, CA: Hunter House CA, 1992.

CURRAH, P.; JUANG, R.; MINTER, S. Transgender rights. Minnesota, MN: University of Minnesita Press, 2006.

FERNÁNDEZ-ROUCO, N.; SÁNCHEZ, F.; GONZÁLEZ, R. Transexualidad y vejez: una realidad por conocer. Revista Kairós Gerontologia, v. 15, n. 5, 15-25, 2012.

FOUCAULT, M. História da sexualidade II: o uso dos prazeres. Rio de Janeiro: Graal, 1984.

História da Sexualidade III: o cuidado de si. Rio de Janeiro: Graal, 1985.

$\overline{1987 / 1999 \text {. }}$

. Vigiar e punir: nascimento da prisão. Trad. Raquel Ramalhete. 20 ed. Petrópolis: Vozes,

. Las Redes del Poder. In: FERRER, Christian (Comp.). E1 linguaje Libertário, V. 1, Montevideo: Editorial Nordan-Comunidad, 1990.

GALLO, S. Repensar a educação: Foucault. Revista Educação \& Realidade, 79-97, 2004.

.; VEIGA-NETO, A. Foucault: filosofia e educação ou Ensaios para uma filosofia da Educação. Educação.: Segmento, n. 3 (Especial Foucault pensa a Educação), p. 16-25, São Paulo, 2007.

GARAIZABAL, C. Transexualidades, identidades e feminismos. In: MISSÉ, M.; COLL-PLANAS, G. (Eds.). El género desordenado: críticas en torno a la patologización de la transexualidad. Barcelona: Egales, 2010.

GARCÍA NIETO, I. Interación de los distintos facrores de exclusión en los adolescentes transexuales: dificuldades para la integración social y laboral. In: CABRERA, O.; CABEZAS, L. (Eds.).

Transexualidad, adolescencias y educación: miradas multidisciplinares. Barcelona, Madrid: Egales Editorial, 2013.

GARCÍA SISO, A. Conflictos de la identidad sexual en la infancia. Revista de la Asociación Española de Neuropsiquiatría, n. 86, 31-46, 2003.

GGB. Mortes violentas de LGBT no Brasil: Relatório, 2017. Disponível em: https://homofobiamata.files.wordpress.com/2017/12/relatorio-2081.pdf

GÓMEZ GIL, E.; ANTONIO, I. Ser transexual. Dirigido al paciente, a su familia, y al entorno sanitario, judicial y social. Barcelona: Glosa, DL, 2006.

.; TRILLA, A.; SALAMERO, M.; GODÁS, T.; VALDÉS, M. Sociodemographic, clinical, and psychiatric characteristics of transsexuals from Spain. Archives of Sexual Behavior, n. 38, 378-392, 2009.

GROELLNER, S. V. A educação dos corpos, dos gêneros e das sexualidades e o reconhecimento da diversidade. Cadernos de Formação RBCE, 71-83, 2010.

GROSSMAN, A.; D’AUGELLI, A.; SALTER, N. Male-to-female transgender youth: gender expression milestones, gender atypicality, victimization, and parents' responses. Journal of GLBT Family Studies, n. 2(1), 71-92, 2006. 
HOOKS, bell. Ensinando a transgredir: a educação como prática de liberdade. Trad. Marcelo Brandão Cipolla. São Paulo: Martins Fontes, 2013.

IGLESIAS HERNÁNDEZ, M. I. et al. Transgender sexual behaviors in a health care. European Psychiatry, n. 25, v. 1, 499, 2010.

JESUS, J. G. Orientações sobre identidade de gênero: conceitos e termos. In: Guia técnico sobre pessoas transexuais, travestis e demais transgêneros, para formadores de opinião, 2012. Disponível em: https://www.sertao.ufg.br/up/16/o/ORIENTA\%C3\%87\%C3\%95ES_POPULA $\%$ C3\%87\%C3\%83O _TRANS.pdf?1334065989

LAWRENCE, A. A. Sexual Orientation versus Age of Onset as Bases for Typologies (Subtypes) for Gender Identity Disorder in Adolescents and Adults. Arch Sex Behav, n. 39, 514-545, 2010.

LEWIS, J.; ARNOLD, M. From multiculturalism to social action. In: COURTLAND, C.; WALZ, G. R. (Eds.). Social action: a mandate for counselors. Virgínia, VA: American Counseling Association and ERIC/CASS, 1998.

LOPES, F. H. Agora, as mulheres são outras: travestilidade e envelhecimento. In: JESUS, J. G. (Ed.). Transfeminismo: teorias e práticas. 2 ed. Rio de Janeiro: Metanoia Editora, 2015.

MIGUEL, T.; VIERGE, S.; ANTONIO, I. Transexualidad, adolescencia y biomedicina: limitaciones del modelo biomédico y perspectivas críticas. In: CABRERA, O.; CABEZAS, L. (Eds.). Transexualidad, adolescencias y educación: miradas multidisciplinares. Barcelona, Madrid: Egales Editorial, 2013.

MISSÉ, M. Transexualidades: outras miradas posibles. 2 ed. Barcelona, Madrid: Egales Editorial, 2014.

MONEY, J. Sex reassignment as related to hermaprhoditism and transsexualism. In: GREEN, R.; MONEY, J. (Eds.). Transsexualism and sex reassignment. Maryland, MD: The Johns Hopkins Press, 1969.

NOGUEIRA, C. A Teoria da interseccionalidade nos estudos de género e sexualidades: condições de produção de "novas possibilidades" no projeto de uma psicologia feminista crítica. In: BRIZOLA, A.; ZANELLA, A.; GESSER, M. (Eds.). Práticas sociais, políticas públicas e direitos humanos. Florianópolis: ABRAPSO - NUPPE/CFH/UFSC, 2013.

OLIVEIRA, J. M. Mil Géneros. Vírus: Revista política e de ideias, n. 7, 74-76, 2015. Disponível em: https://www.academia.edu/13655649/Mil_G\%C3\%A9neros_A_thousand_genders

PANTERAS ROSA (2006). A vergonha que se esperava. Disponível em: http://www.panterasrosa.blogspot.pt/2006_07_01_archive.html

PEREIRA, M. M. Fazendo género no recreio: a negociação do género em espaço escolar. Lisboa: ICS, 2012.

PLATERO, R. L. Trans*exualidades: acompañamiento, factores de salud y recursos educativos. Barcelona: Edicions Bellaterra, 2014.

ROBERTS, A.; ROSARIO, M.; CORLISS, H.; KOENEN, K.; AUSTIN, B. Childhood gender nonconformity: a risk indicator for childhood abuse and posttraumatic stress in youth. Pediatrics, n. 129, v. 3, 410-417, 2012. 
RODRIGUES, L. Viagens trans (género) em Portugal e no Brasil: uma aproximação psicológica feminista crítica. Tese de Doutoramento em Psicologia. Faculdade de Psicologia e de Ciências da Educação da Universidade do Porto, 2016.

; CARNEIRO, N. S.; NOGUEIRA, C. Violência transfóbica: aproximações críticas e horizontes de resistência. In: NEVES, S.; COSTA, D. (Eds.). Violência de género. Lisboa: CIEG, 2017.

SANTOS. B. S. Decolonizar el saber, reiventiar el poder. Montevideo: Trilce, 2010.

SAUSA, L. Translating research into practice: trans youth recommendations for improving school systems. Journal of Gay and Lesbian Issues in Education, n. 3, v. 1, 15-28, 2005.

SENNOTT, S. Gender disorder as gender oppression: a transfeminist approach to rethinking the pathologization of gender non-conformity. Women \& Therapy, n. 34, v. 1-2, 93-113, 2011.

TGEU. Trans murder monitoring, 2016. Disponível em: https://transrespect.org/en/research/transmurder-monitoring/

TIBURI, M. Filosofia em comum: para ler-Junto. Rio de Janeiro: Record, 2008.

VEIGA-NETO, A. Foucault e a educação. Belo Horizonte: Autêntica, 2003.

. Educar como arte de governar. Currículo sem Fronteiras, n. 11, v. 1, 5-13, 2011.

WHITTLE, S. Foreword. In: STRYKER, S.; WHITTLE, S. (Eds.). The transgender studies reader.

New York, NY: Routledge, 2006.

WITTEN, T. M. Life course analysis: the courage to search for something more: Middle adulthood issues in the transgender and intersex community. Journal of Human Behavior in a Social

Environment, n. 8, v. 3-4, 189-224, 2004.

ZUCKER, K.; BRADLEY, S. Gender identity disorder and psychosexual problems in children and adolescents. New York, NY: Guilford Press, 1995. 